\title{
Clinical profile of children with Severe Acute Malnutrition attending Nutritional Rehabilitation Centre in Dharmapuri
}

\author{
Ganesh $\mathbf{J}^{1}$, Kumaravel K $\mathbf{S}^{2}$, Balaji $\mathbf{J}^{3}$, Rameshbabu $\mathbf{B}^{4}$, Nedunchelian $\mathbf{K}^{5}$ \\ ${ }^{1}$ Ganesh J, ${ }^{2}$ Kumaravel K S, ${ }^{3}$ Balaji J, ${ }^{4}$ Rameshbabu B, ${ }^{5}$ Nedunchelian K. From Govt Dharmapuri Medical College, \\ Dharmapuri, Tamilnadu
}

Address for correspondence: Dr Kumaravel K S, Email: kumaravelks10@gmail.com

\begin{abstract}
Introduction: Prevalence of severe acute malnutrition is estimated to be $2.6 \%$ among Under 5 years children globally and is estimated to be $6.4 \%$ in India as per National Family Health Survey -3 . Methodology: This study was conducted to find the clinical profile of children from 6 months to 60 months of age admitted in Nutritional Rehabilitation Centre. Results: The Prevalence of SAM was 5.1\%. 77.3\% had Wt/Length criteria satisfied. 2.7\% had mid arm circumference criteria satisfied. Edema was not observed. The Peak Prevalence of SAM was found in the age group between 6 months to 12 months. Sepsis, Bronchopneumonia and other infections were found to be more common in children with SAM. The average duration of stay was 7.02 days. The average weight gain for children under treatment was $8.9 \mathrm{gm} / \mathrm{kg} / \mathrm{day}$. There were no cases of relapse noted in our study period. Conclusion: Weight/Height ratio is the best among the three criteria for identifying SAM. The shorter duration of stay in NRC is a major handicap to the outcome. Establishment of $\mathrm{NRC}$ in all medical college hospitals with skilled personnel will be a major investment our country makes to ensure the future of its children.
\end{abstract}

Keywords: Severe Acute Malnutrition, National Rural Health Mission, Nutritional Rehabilitation Centre, Mid Upper Arm Circumference.

\section{Introduction}

Some form of malnutrition has been reported in up to $33 \%$ of children in developing countries. Severe Acute Malnutrition (SAM) is defined as a weight-for-height measurement of $70 \%$ or less below the median, or three SD or more below the mean National Centre for Health Statistics reference values, the presence of bilateral pitting oedema of nutritional origin, or a mid-upper-arm circumference of less than $110 \mathrm{~mm}$ in children age 1-5 years [1]. Prevalence of SAM is estimated to be $2.6 \%$ among children less than 5 years globally and is estimated to be $6.4 \%$ in India as per National Family Health Survey $-3[2]$. Underweight in children is found to be $25-34 \%$ among five children and is more than 40 $\%$ in states like Uttar Pradesh and Madhya Pradesh. Risk of mortality is increased by 9 times in children with severe acute malnutrition [3]. The median case fatality rate is approximately $23.5 \%$ in severe malnutrition, reaching $50 \%$ in edematous malnutrition [4].

Manuscript received: $28^{\text {th }}$ Jan 2016 Reviewed: $09^{\text {th }} \mathrm{Feb} 2016$

Author Corrected; $20^{\text {th }} \mathrm{Feb} 2016$

Accepted for Publication: $29^{\text {th }}$ Feb 2016
Nutritional Rehabilitation Centres (NRC) are set up in India to facilitate therapeutic care for SAM children as per WHO Protocol. Here these children have inpatient management by trained personnel and counselling to the mothers was also given. They are discharged once they meet the discharge criteria and are advised regular follow-up at the field level [5]. Nutritional Rehabilitation Centre in Dharmapuri was established in June 2013 under the auspices of National Rural Health Mission. The centre has a 10 bedded ward, one Acute Care Room, Kitchen, Formula Preparation Room and a training room. The centre was manned by a Nodal Officer, 4 Staff Nurses, Nutrition Counselor, 2 Multipurpose Workers and 2 cooks.

This study was conducted to find out the clinical profile of children admitted in Nutritional Rehabilitation Centre.

\section{Aim of the study:}

The aim of the study is to 
1. Identify children with SAM and find how these children fulfill each of the WHO criteria.

2. Assess the clinical profile of SAM children.

\section{Material and Methods}

This study was conducted as a descriptive study at Nutritional Rehabilitation Centre, Government Dharmapuri Medical College and hospital, Dharmapuri. Children between 6 months to 60 months were included in the study from September 2013 to May 2014. In the NRC, age, sex, height/length, weight, Mid Upper Arm Circumference (MUAC), presence of edema and other complications were recorded.

\section{Operational Definitions:}

1. Severe Acute Malnutrition[1]:

a. Weight/height or weight/length $<3 \mathrm{SD}$ or weightfor-height measurement of $70 \%$ or less below the median

b. Mid-upper arm circumference $<115 \mathrm{mms}$

c. Bipedal edema of nutritional origin.

2. Complicated SAM (1): Presence of Anorexia, fever, hypothermia $(<35 \mathrm{C})$, persistent vomiting, severe dehydration, not alert, apathetic, unconscious, convulsions, hypoglycemia, severe anemia, severe pneumonia or extensive superficial infection. The operational guidelines were followed for case definitions of complicated SAM [1].

\section{Results (Tables 1-4)}

The total number of admissions in the 6 months to 60 months age group between September 2013 and May 2014 was 2142 in our hospital, out of which 110 children (5.1\%) had SAM. Sex distribution was almost equal for SAM children (M: $\mathrm{F}=48.2 \%: 51.8 \%$ ). $91 \%$ of the children brought by their mothers were not aware that their children had a primary nutritional problem. On assessing criteria for diagnosis of SAM by WHO criteria, 85 children (77.3\%) had Weight/Length (or height) criteria satisfied whereas only 3 children (2.7\%) had Mid Arm Circumference criteria satisfied. Both criteria were present in 22 children (20\%). There was no child observed to have nutritional edema.

The Peak Prevalence of SAM was found in the age group between 6 months to 12 months (30.9\%) followed by $13-24$ months $(21 \%)$.

Among the morbidity pattern viral infections (21.4\%) was found to be the commonest disease for which they were hospitalized. Viral infections among SAM children were 17.3\%. Acute watery diarrhea was the second commonest condition, $13.4 \%$ in normal children compared to $14.5 \%$ in SAM children. Third commonest cause of admission was lower respiratory tract infections, $8.8 \%$ in normal children, whereas it was $10 \%$ in SAM children.

Sepsis was a cause of admission in only $1.5 \%$ of admission of normal children whereas it was $9 \%$ in SAM children. Bronchopneumonia for normal children was around 3.7\% whereas for SAM children it was around 5.4\%. Measles as a cause of admission was found to be $4.3 \%$ in normal children, whereas for SAM children it was 3.6\%. Though Sepsis, Bronchopneumonia and Measles were higher in SAM children, the strength of association was not statistically significant. Acute CNS infection was seen in $0.7 \%$ of normal children admitted whereas it was $5.4 \%$ in SAM children. Anemia was seen in $0.7 \%$ of normal children and in $3.6 \%$ of SAM children. . Developmental delay was identified in 
Table 1: Clinical Profile

\begin{tabular}{|l|l|l|l|}
\hline \multicolumn{2}{|l|}{ Total no of admissions in children ward } & 2142 \\
\hline SAM & SAM & $110(5.1 \%)$ \\
\hline MAM & $\begin{array}{l}\text { Male } \\
\text { N (\%) }\end{array}$ & $251(11.7 \%)$ \\
\hline \multirow{2}{*}{ Weight/Height } & $36(42.1)$ & $\begin{array}{l}\text { Female } \\
\text { N (\%) }\end{array}$ & $\begin{array}{l}\text { Total N } \\
(\%)\end{array}$ \\
\hline MUAC & 0 & $49(57.6)$ & $\begin{array}{l}85 \\
(77.3)\end{array}$ \\
\hline Both & $17(77.3)$ & $3(100)$ & $3(2.7)$ \\
\hline Pedal Edema & 0 & $5(22.7)$ & $22(20)$ \\
\hline Total & $53(48.2)$ & 0 & 0 \\
\hline \multirow{2}{*}{ Age Group } & Male (\%) & \multicolumn{2}{|l|}{} \\
\hline
\end{tabular}

Table 2: Morbidity pattern of SAM children in comparison with well nourished children

\begin{tabular}{|l|l|l|}
\hline Morbidity & Well Nourished Children (\%) & SAM (\%) \\
\hline Viral Fever & $172(21.4)$ & $19(17.3)$ \\
\hline Acute Watery Diarrhoea & $108(13.4)$ & $16(14.5)$ \\
\hline Lower respiratory tract infection & $71(8.8)$ & $11(10)$ \\
\hline Sepsis & $12(1.5)$ & $10(9)(\mathrm{p}=0.70)$ \\
\hline Enteric Fever & $58(7.2)$ & $10(9)$ \\
\hline Febrile Seizure & $92(11.5)$ & $7(6.4)$ \\
\hline Acute cns infection & $6(0.7)$ & $6(5.4)(\mathrm{p}=0.001)$ \\
\hline Bronchopneumonia & $30(3.7)$ & $5(4.5)$ \\
\hline CHD & $5(0.6)$ & $5(4.5)(\mathrm{p}=0.70)$ \\
\hline Seizure Disorder & $83(10.3)$ & $4(3.6)$ \\
\hline Anemia & $6(0.7)$ & $4(3.6)(\mathrm{p}=0.01)$ \\
\hline Measles & $35(4.3)$ & $3(2.7)$ \\
\hline Scrub typhus & $35(4.3)$ & $3(2.7)$ \\
\hline Developmental Delay & $4(0.5)$ & $3(2.7)(\mathrm{p}=0.01)$ \\
\hline Urinary Tract Infection & $8(0.9)$ & $1(0.9)$ \\
\hline Viral Hepatitis & $22(2.7)$ & $1(0.9)$ \\
\hline Dengue & $53(6.6)$ & $1(0.9)$ \\
\hline HIV & $3(0.4)$ & $1(0.9)$ \\
\hline Total & 803 & 110 \\
\hline
\end{tabular}


Table 3: Outcome of SAM children

\begin{tabular}{|l|l|l|l|}
\hline Outcome & Male (\%) & Female (\%) & Total (\%) \\
\hline Discharged & $47(49.5)$ & $48(50.5)$ & $95(86.4)$ \\
\hline Recovered & $12(52.2)$ & $11(47.8)$ & $23(24.2)$ \\
\hline Defaulter & $15(35.7)$ & $27(64.3)$ & $42(38.2)$ \\
\hline Died & $6(40)$ & 9 & $15(13.6)$ \\
\hline
\end{tabular}

Table 4: Duration of stay

\begin{tabular}{|l|l|l|l|}
\hline$<7$ Days & $36(43.9)$ & $46(56.1)$ & $82(74.5)$ \\
\hline 7 TO 15 Days & $13(56.5)$ & $10(43.5)$ & $23(21)$ \\
\hline$>$ 15 Days & $2(40)$ & $3(60)$ & $5(4.5)$ \\
\hline Average weight gain $=8.9 \mathrm{gm} / \mathrm{kg} / \mathrm{day}$ & \\
\hline Mean duration of stay $=7.02$ days \\
\hline
\end{tabular}

$0.5 \%$ of normal children whereas it was $2.7 \%$ in SAM children. Anemia, Acute CNS infection and Developmental Delay were found to be more in the SAM children than well nourished children and this is statistically significant.. Developmental delay was identified in $0.5 \%$ of normal children whereas it was $2.7 \%$ in SAM children. Anemia, Acute CNS infection and Developmental Delay were found to be more in the SAM children than well nourished children and this is statistically significant.

The incidence of febrile seizures, seizure disorder, scrub typhus, viral hepatitis and Dengue were found to be more in nutritionally normal children compared to SAM children. The average duration of stay in the hospital was 7.02 days. The average weight gain for children under treatment was $8.9 \mathrm{gm} / \mathrm{kg} /$ day. There were no cases of relapse noted in our study period.

\section{Discussion}

SAM remains as a most important determinant of mortality and morbidity of Under 5 year children. The prevalence of SAM in our NRC was $5.1 \%$. National prevalence of SAM at community level is $6.8 \%$ [1]. This value is only the tip of the ice berg as only children with complications access health care facility. Sepsis was seen in about $9 \%$ of children with SAM, which was comparable to a Columbian study which also reported a similar incidence [6]. The occurrence of serious bacterial infections like acute CNS infection were more in SAM children compared to admitted children without malnutrition. Viral infection was found to be more in well nourished children. 91\% of SAM children in our study were found to have an illness as compared to Singh et al study which reported only $36.9 \%$ [7].

The recovery rate of weight gain in our study was $24.2 \%$ as compared to Singh et al study who documented a recovery rate of $46.8 \%$ [7]. The defaulter rate was $38.2 \%$ in our study compared to Singh et al in which it was $47.2 \%$. The major handicap was that the parents were not able to be on admission for a longer duration because of various social/ economical aspects (74.1\% stayed in NRC for $<7$ days). A study by Dasgupta $R$ et al also concluded the difficulty faced by nutritional rehabilitation centers where the failure rates are also attributed to social issues in Madhya Pradesh and the failure to identify chronic malnutrition as a medical problem [8]. 22.7\% children were not gaining adequate weight of $>5 \mathrm{mg} / \mathrm{kg} /$ day compared to Mayura et al study which had $15.5 \%$ [9]. The death rate in our study was $13.6 \%$. The average duration of stay was 7.02 days in our study. On comparing with a study made by Maurya et al, the duration of study was 6.8 days [9]. Similarly the average weight gain in that study was $9 \mathrm{~g} / \mathrm{kg} /$ day whereas it was $8.9 \mathrm{~g} / \mathrm{kg} / \mathrm{day}$ in our study. A study by Syed Tariq A et al reported a weight gain of $5.5 \mathrm{~g} / \mathrm{kg} /$ day [10].

\section{Conclusion}

As evident from the study, Weight/Height ratio is the best among the three criteria for identifying SAM. So 
this criterion should be emphasized to all health care workers and medical students for early identification of SAM. In our study we were able find out the causes of morbidity of Severe Acute Malnutrition children in our hospital. The shorter duration of stay in NRC is a major handicap to the outcome as the parents prefer leaving earlier due to various socio economic reasons. This hurdle can be overcome by strategies like offering incentives/stipend to the parents during the stay period. After the reduction in the prevalence of Malnutrition in the state of Tamilnadu, the need for establishment of separate NRC was always under debate. Yet provision of skilled therapeutic nutritional care, guidance and counseling were beyond the reach of children with SAM. It is at this juncture the role of NRC proves its importance. Establishment of NRC in all medical college hospitals and institutions with skilled personnel will be a major investment our country makes to ensure the future of its children.

Acknowledgements: We are grateful to the clinical and nursing staff of NRC, Govt Dharmapuri Medical College, Dharmapuri, Tamilnadu. We thank the State NRHM coordinator Dr.Srinivasan, for his support and guidance in establishing this NRC.

Funding: No funding sources, Conflict of Interest: None declared

Ethical approval: The study was approved by the institutional ethics committee

\section{References}

1. Operational Guidelines on Facility Based Management of Children with Severe Acute Malnutrition, Ministry of Health and Family Welfare, Government of India, 2011. Available from: http://www.nihf.org/NCHRC-Publications/ Operational Guidelines.

2. International Institute for Population Sciences (IIPS) and Macro International. National Family Health Survey (NFHS-3), 2005-2006. Mumbai: IIPS; 2007.
3. United Nations Children's Fund (UNICEF). Tracking progress on child and maternal nutrition. A survival and development priority. New York: United Nations Children's Fund (UNICEF); 2009.

4. Ashworth A, Khanum S, Jackson A, Schofield C. Guidelines for the inpatient treatment of severely malnourished children. Geneva: World Health Organisation; 2003.

5. World Health Organization (WHO), United Nations Children's Fund (UNICEF). WHO Child Growth Standards and the identification of severe acute malnutrition in infants and children. Geneva, Switzerland: World Health Organization and the United Nations Children's Fund; 2009.

6. Bernal $\mathrm{C}$, Velásquez $\mathrm{C}$, Alcaraz $\mathrm{G}$, Botero $\mathrm{J}$. Treatment of severe malnutrition in children: experience in implementing the world health organization guidelines in turbo, Colombia. J Pediatr Gastroenterol Nutr. 2008;46:322-8.

7. Singh K, Badgaiyan N, Ranjan A, Dixit HO, Kaushik A, Aguavo VM, et al. Management of children with severe acute malnutrition in India; Experience of nutritional rehabilitation centre in Uttar Pradesh, India. Indian Pediatr. 2013;51:21-5.

8. Dasgupta R, Ahuja S, Yumnam V. Can nutrition rehabilitation centers address severe malnutrition in India?

Indian Pediatr. 2014 Feb;51(2):95-9.

9. Maurya, Et Al. Management Of Sam In Children Aged 6-59 Months Indian Pediatrics Volume 51 June 15,2014

10. Syed Tariq A et al, Demographic, clinical profile of severe acute malnutrition and our experience of nutrition rehabilitation centre at children hospital Srinagar Kashmir. Int J Contemp Pediatr 2015;2:233-7.

\section{How to cite this article?}

Ganesh J, Kumaravel K S, Balaji J, Rameshbabu B, Nedunchelian K. Clinical profile of children with Severe Acute Malnutrition attending Nutritional Rehabilitation Centre in Dharmapur: Int J Pediatr Res 2016; 3(2):95-99.doi: 10.17511/ijpr.2016.i02.05. 